Methods: Individual patient-level variables were obtained from a single institution TKR and THR registry between 5/1/07 and 2/1/11. Western Ontario and McMaster Universities Osteoarthritis Index (WOMAC) pain and function scores at baseline and 2 years after elective TKR and THR were collected and retrospectively analysed. We included patients living in New York, Connecticut and New Jersey which is the catchment area for the hospital. Individuals' geocodable addresses were used to obtain the number of primary care physicians (PCPs) and specialists in each census tract using the ArcGIS software. Provider density was calculated and broken down into percentage quartiles. Comparisons were made using Kruskal-Wallis tests.

Results: A total of 3606 TKR, and 4295 THR patients were included. (figure 1) Mean number of PCPs were 5.4(SD 9.5) and specialists were 15.8(SD 41.1) per census tract. The median number of PCPs were $2($ IQR 1,6) and specialists were 3 (IQR 1, 13). Neighbourhood poverty or education correlated poorly with the number of PCPs and specialists. Baseline WOMAC pain and function scores (table 1) are statistically significantly better in neighbourhoods with a higher proportion of specialists, but not PCPs. These differences were no longer present 2 years after surgery.

Abstract OP0338 - Table 1 Association of specialist proportions in neighbourhoods with WOMAC* scores

\begin{tabular}{|c|c|c|c|c|c|c|c|c|}
\hline $\begin{array}{l}\text { Proportion } \\
\text { of } \\
\text { Specialists } \\
\text { per census } \\
\text { tract }\end{array}$ & $\begin{array}{l}\text { Baseline } \\
\text { wOMAC* } \\
\text { median } \\
{[1 \mathrm{QR}]}\end{array}$ & $\begin{array}{l}\text { p-value } \\
\text { pals }\end{array}$ & $\begin{array}{l}\text { 2-year } \\
\text { WOMAC* } \\
\text { median [IQR] }\end{array}$ & $\begin{array}{l}\text { p-value } \\
\text { pals }\end{array}$ & $\begin{array}{l}\text { Baseline } \\
\text { WOMAC* } \\
\text { median } \\
{[\backslash \mathrm{QR}]}\end{array}$ & p-value & $\begin{array}{l}\text { 2-year } \\
\text { WOMAC* } \\
\text { median } \\
{[[Q R]}\end{array}$ & $\begin{array}{ll}\text { p-value } \\
\end{array}$ \\
\hline Pain & \multicolumn{4}{|c|}{ Total Hip Replacement } & \multirow{2}{*}{\multicolumn{4}{|c|}{ Total Knee Replacement }} \\
\hline & & $<0.001$ & & 0.59 & & & & 0.76 \\
\hline $\begin{array}{l}\text { Quartile } 1 \\
\text { (Lowest) }\end{array}$ & $50[40,65]$ & & $100[90,100]$ & & $50[40,65]$ & & $95[80,100]$ & \\
\hline Quartie 2 & $\frac{50[40,65]}{55(4565]}$ & & $100[90,100]$ & & $55[40,65]$ & & & \\
\hline Quartile 3 & $\frac{55[45,65]}{55 / 4565}$ & & $\frac{100[90,100]}{10090100}$ & & $\frac{55[45,65]}{563(1570)}$ & & $\frac{95[85,100]}{95 / 80.00]}$ & \\
\hline $\begin{array}{l}\text { Quartile } 4 \\
\text { (Highest) }\end{array}$ & $55[45,65]$ & & $100[90,100]$ & & & & & \\
\hline Function & \multicolumn{4}{|c|}{ 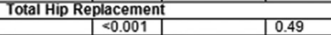 } & \multirow{2}{*}{\multicolumn{4}{|c|}{$\begin{array}{l}\text { Total Knee Replacement } \\
\qquad<0.001 \mid\end{array}$}} \\
\hline & & & & 0.49 & & & & \\
\hline (Lowest) & {$[35.3,58.8]$} & & {$[86.8,100.0]$} & & {$[39.7,61.8]$} & & [75. 0.98 .4$]$ & \\
\hline Quartile 2 & $\begin{array}{l}48.5 \\
{[36.8 .61 .8]}\end{array}$ & & $\begin{array}{l}95.6 \\
{[86.8 .100 .0]}\end{array}$ & & $\begin{array}{l}52.9 \\
{[42.7 .66 .2]}\end{array}$ & & $\begin{array}{l}90.6 \\
76.5 .97 .1]\end{array}$ & \\
\hline Quartile 3 & $\begin{array}{l}50.0 \\
{[39.7,64.7]}\end{array}$ & & $\begin{array}{l}96.9 \\
{[88.2,100.0]}\end{array}$ & & $\begin{array}{l}52.9 \\
{[42.7 .66 .2]}\end{array}$ & & $\begin{array}{l}89.9 \\
{[77.9 .97 .1]}\end{array}$ & \\
\hline $\begin{array}{l}\text { Quartile } 4 \\
\text { (Highest) }\end{array}$ & $\begin{array}{l}50.0 \\
{[39.4,63.3]}\end{array}$ & & $\begin{array}{l}96.9 \\
{[88.2,100.0]}\end{array}$ & & [44.9.1.69.1] & & $\begin{array}{l}91.2 \\
{[78.3,98.5]}\end{array}$ & \\
\hline
\end{tabular}

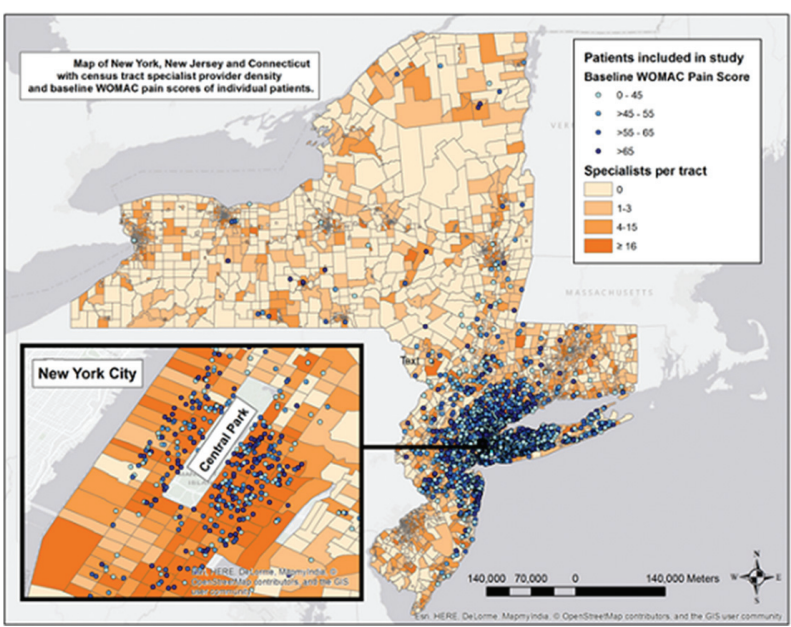

Abstract OP0338 - Figure 1 Map of New York, New Jersey and Connecticut with census tract specialist provider density and baseline WOMAC pain scores of individual patients.

Conclusions: Patients from neighbourhoods with fewer specialists seek arthroplasty with worse baseline pain and function than those from neighbourhoods with more specialists. However, once these patients receive arthroplasty (i.e. specialty care), these differences resolve by 2 years. These data suggest that once a patient can access specialty care in the health care system, their outcomes improve despite worse baseline pain and function.

Disclosure of Interest: B. Mehta: None declared, J. Szymonifka: None declared, S. Dey: None declared, I. Navarro-Millan: None declared, L. Mandl Grant/research support from: Boehringer-Ingelheim, A. Bass Grant/research support from: Abbott, Pfizer, L. Russell: None declared, M. Parks Grant/research support from: Zimmer, Consultant for: Zimmer, M. Figgie Shareholder of: Mekanika, J. Nguyen: None declared, S. Goodman: None declared

DOI: 10.1136/annrheumdis-2018-eular.5742

\section{OP0339 \\ DEVELOPMENT OF A PREDICTIVE MODEL OF RADIOLOGICAL DAMAGE IN PATIENTS WITH RHEUMATOID ARTHRITIS BASED ON ARTIFICIAL INTELLIGENCE}

J.M. Lezcano ${ }^{1}$, J. Ivorra-Cortes ${ }^{2}$, R. López Mejías ${ }^{3}$, J. Martín ${ }^{4}$, B. FernandezGutiérrez $^{1}$, M.A. González-Gay ${ }^{3}$, A. Balsa ${ }^{5}$, I. González-Álvaro ${ }^{6}$, F. Salazar ${ }^{7}$ L. Abásolo', L. Rodriguez-Rodriguez ${ }^{1}$. ${ }^{1}$ Hospital Clinico San Carlos, Madrid; ${ }^{2}$ Hospital La Fe, Valencia; ${ }^{3}$ Hospital Marqués de Valdecilla, Santander, ${ }^{4}$ Instituto López-Neyra, Granada; ${ }^{5}$ Hospital de La Paz; ${ }^{6}$ Hospital de la Princesa e IIS-IP; ${ }^{7}$ CIMNE, Madrid, Spain

Background: Rheumatoid arthritis (RA) is a chronic inflammatory disease associated with increased mortality and disability. Although different factors associated with prognosis have been identified, it is still difficult to predict the evolution of a specific patient.

Objectives: Our objective is to train and validate a predictive model of disease severity using radiological damage as a surrogate marker, based on Artificial Intelligence techniques, and using clinical and genetic data.

Methods: Four independent cohorts were included (892 patients with 1667 hand X-rays). Radiological damage was measured with the Sharp/van-der-Heijde score (SvdH). The variables to be predicted [total value of $\mathrm{SvdH}$, erosion component (ES) and joint narrowing (NS)] were logarithmically transformed. As clinical predictors, age at onset of symptoms, sex, duration of the disease at the time of each radiograph, year of onset of symptoms and presence of rheumatoid factor were used. As genetic variables, the single nucleotide polymorphism data obtained from the Immunochip genotyping platform (Illumina) were used. In addition, an interaction between each polymorphism and the duration of the disease was introduced. Three cohorts were used for the selection of variables, generation of predictive models and internal validation. The fourth cohort was used to perform the external validation of the models. Regression trees with random effects were generated using the $\mathrm{R}$ package 'REEMtree'. The goodness of fit of the models was measured using the root mean squared error (RMSE) and the intraclass correlation coefficient (ICC).

Results: In the cohorts where the predictive models were developed, the RMSEs for total SvdH, ES and NS were 3.16, 1.02 and 2.29 units of the Sharp/van-derHeijde score, respectively. The ICCs were $0.96,0.87$ and 0.95 , respectively. In the external validation cohort, the RMSEs were $7.13,3.53$ and 4.81 units of the Sharp/van-der-Heijde score, respectively. The ICCs were $0.90,0.78$ and 0.88 .

For the total SvdH, the best fit model contained the variables 'age of onset of the symptoms of RA' and the interaction between duration of the disease and 3 polymorphisms: rs10752907, rs4405161 and rs2501617. For the ES, it contained the variables 'age of onset of AR symptoms', the polymorphism rs7769752 and the interaction between disease duration and 6 polymorphisms: rs 12410412 , rs117029499, rs72925969, rs869186, rs11258464, rs4781952. For the NS, it contained the variables 'age of onset of AR symptoms', 'gender', and the interaction between disease duration and 9 polymorphisms: rs3814055, rs 1020822 , rs13157991, rs152294, rs2914190, rs10824537, rs2637229, rs114136906 and rs4958241.

Conclusions: It is possible to generate predictive models of radiological damage of great precision using Artificial Intelligence techniques. This could allow early stratification of patients according to prognosis

It is necessary to validate these models in other populations.

Disclosure of Interest: None declared

DOI: 10.1136/annrheumdis-2018-eular.6801

\section{FRIDAY, 15 JUNE 2018}

\section{From big data to personalised medicine in paediatric rheumatic diseases.}

\section{OP0340 EVIDENCE BASED RECOMMENDATIONS FOR CORTICOSTEROID TAPERING/DISCONTINUATION IN NEW ONSET JUVENILE DERMATOMYOSITIS PATIENTS FROM THE PRINTO TRIAL}

G. Giancane, C. Lavarello, A. Pistorio, F. Zulian, B. Magnusson, T. Avcin,

F. Corona, V. Gerloni, S. Pastore, R. Marini, S. Martino, A. Pagnier, M. Rodiere

C. Soler, V. Stanevicha, R. Ten Cate, Y. Uziel, J. Vojinovic, E. Fueri, A. Ravelli,

A. Martini, N. Ruperto, on behalf of PRINTO. Clinica Pediatrica e Reumatologia -

PRINTO, Istituto Giannina Gaslini, GENOA, Italy

Background: At present no clear evidence based guidelines exist to standardise the tapering and discontinuation of corticosteroids (CS) in juvenile dermatomyositis (JDM).

Objectives: To provide evidence-based recommendations for CS tapering/discontinuation through the analysis of the patients in the PRINTO new onset JDM trial. Secondary objective of the study was to identify predictors of clinical remission and CS discontinuation. 
Methods: New onset JDM children were randomised to receive either prednisone (PDN) alone or in combination with MTX or CSA. All children were given initially intravenous methylprednisolone, and then PDN starting with $2 \mathrm{mg} / \mathrm{kg} /$ day. Gradual tapering according to a specific protocol could lead to the safe dose of $0.2 \mathrm{mg} /$ $\mathrm{kg} /$ day by month 6 , then discontinued at month 24 . Major therapeutic changes (MTC) were defined as the addition or major increase in the dose of MTX/CSA/ other drugs or any other reasons for which patients were dropped from the trial. Patients were divided according to clinical remission (CR) $(C M A S=52$ and MD global=0 for 6 continuous months) into two major groups. Group 1 included those on CR, who could discontinue PDN, with no MTC (reference group). Group 1 was compared with those who did not achieve CR, without or with MTC (group 2 and 3, respectively). JDM core set measures (CSM) were compared within the 3 groups. We also calculated the gold standard group 1 median change in the CSM in the first 6 and over 24 months and applied a logistic regression model to identify predictors of $\mathrm{CR}$ with PDN discontinuation.

Results: 139 children were enrolled in the trial: 47 on PDN, 46 on PDN +CSA and 46 on PDN +MTX. We identified 30 (21.6\%) patients for group 1, $43(30.9 \%)$ for group 2 and $66(47.5 \%)$ for group 3 . At baseline all 3 groups had no differences in the CSM. Already in the first 2 months a clear differential trend in disease activity measures, according to clinical remission status and PDN discontinuation, could be identified. From the observation of the median change in the CSM of group 1 in the first 6 months, the following recommendations could be extrapolated: decrease corticosteroids from 2 to $1 \mathrm{mg} / \mathrm{kg} /$ day in 2 months if the MD-global, parent-global, CHAQ, DAS, CMAS, MMT or Phs measures have changed of at least $50 \%$; from 1 to $0.5 \mathrm{mg} / \mathrm{kg} /$ day in the following 2 months if the MD-global, CHAQ, DAS, CMAS show a change of at least $20 \%$; in the following 2 months (month 4-6) corticosteroids can be tapered up to the safe dose of $0.2 \mathrm{mg} /$ $\mathrm{kg} /$ day, if the disease activity measures remain at low/normal values. We finally ran a logistic regression model that showed that the achievement of PRINTO criteria 50-70-90 at 2 months from disease onset, an age at onset $>9$ years and the combination therapy PDN +MTX, increase the probability of clinical remission from 4 to 7 times (table 1 ).

Abstract OP0340 - Table 1 Logistic regression model for the outcome: achievement of remission (n/tot: 28/130; 21.5\%)

$\mathrm{OR}(95 \% \mathrm{CI}) \quad \mathrm{P}$

Responder at 2 months:

0.0076

Printo-50 ( $v$ s. not responder/Printo-20)

$5.41(1.37-21.32)$

Printo-70 (vs. not responder/Printo-20)

$6.90(1.91-24.99)$

Printo-90 (vs. not responder/Printo-20)

$4.46(1.08-18.38)$

Age at onset $>8.53$ years $(\leq 8.53$ years)

$4.64(1.69-12.71)$

0.0017

Treatment group: $\mathrm{PDN}+\mathrm{MTX}$ (vs $\mathrm{PDN} / \mathrm{PDN}+\mathrm{CSA})$

$3.63(1.30-10.09)$

0.0116

AUC of the model: 0.80

OR: Odds Ratio; 95\% CI: 95\% Confidence Interval; P\#. Likelihood Ratio test.

Conclusions: We propose evidence based specific cut-offs for corticosteroid tapering/discontinuation based on the change in JDM CSM of disease activity, and to identify the best predictors for clinical remission and corticosteroid discontinuation.

Disclosure of Interest: None declared

DOI: 10.1136/annrheumdis-2018-eular.3750

FRIDAY, 15 JUNE 2018

Triple T: T cells, technologies and therapies

\section{OP0341 INCREASED FREQUENCY OF CIRCULATING CD4 +CXCR5-PD1HI PERIPHERAL HELPER T (CTPH) CELLS IN PATIENTS WITH SEROPOSITIVE EARLY RHEUMATOID ARTHRITIS (RA)}

P. Fortea-Gordo ${ }^{1}$, L. Nuño ${ }^{1}$, A. Villalba ${ }^{1}$, D. Peiteado ${ }^{1}$, I. Monjo ${ }^{1}$, P. SanchezMateos $^{2}$, A. Puig-Kröger ${ }^{2}$, E. de Miguel ${ }^{1}$, A. Balsa ${ }^{1}$, M.E. Miranda Carus ${ }^{1}$. ${ }^{1}$ Rheumatology, Hospital La Paz - IdiPAZ; ${ }^{2}$ Immuno-oncology, Hospital Gregorio Marañon, Madrid, Spain

Background: A novel population of CD4 + T cells with B cell helping capacity has been described in the synovial tissues and peripheral blood of seropositive RA patients with an established disease, and termed 'peripheral helper' (Tph) cells. (Rao DA et al, Nature 2017) Tph cells are characterised by the lack of CXCR5 together with a bright expression of PD-1 (CD4 +CXCR5-PD-1 ${ }^{\text {hi }} \mathrm{T}$ cells). As opposed to CD4 +CXCR5+PD-1 ${ }^{\text {hi }}$ follicular helper T cells (Tfh), Tph cells are not located in lymphoid organs but accumulate in inflamed tissues. Tph cell numbers have not been previously examined in early RA (eRA).

Objectives: To study the frequency of circulating CD3 +CD4+CXCR5-PD- $1^{\text {hi }}$ Tph cells (cTph), in patients with eRA.

Methods: Peripheral blood was drawn from DMARD-naïve early RA patients (eRA) (2010 ACR criteria) with a disease duration $<24$ weeks $(n=42)$, and healthy controls $(\mathrm{HC})$ matched for age and gender $(n=42)$. For comparison, blood was also drawn from 66 patients with established RA (disease duration >2 years), 45 patients with Spondyloarthritis ( $\mathrm{SpA}$ ), and their age and gender-matched $\mathrm{HC}$ (one $\mathrm{HC}$ per patient). In addition, synovial fluid from 7 patients with established RA and 3 patients with SpA was examined. Established RA patients were receiving lowdose oral methotrexate and were naïve for biological agents. SpA patients were receiving NSAIDs, low-dose oral methotrexate and/or sulphasalazine and were naïve for biologicals. After isolation by Ficoll-Hypaque gradient, PBMCs were stained with antibodies to CD3, CD4, CXCR5, ICOS and PD-1, and examined by flow cytometry.

Results: The frequency of circulating CXCR5- cells gated for CD4 +T cells was not different among the studied groups. In contrast, eRA patients demonstrated an increased frequency of circulating CD4 +CXCR5-PD-1 ${ }^{\text {hi }}$ Tph and CD4 +CXCR5-PD-1 ${ }^{\text {hi } I C O S+T}$ cells. When examining seropositive (RF +and/or $A C P A+, n=25$ ) and seronegative eRA patients (RF- and ACPA-, $n=17$ ) separately, it was evident that the above described alterations were only apparent in seropositive eRA. Likewise, increased cTph numbers were observed in seropositive $(n=47)$ but not seronegative $(n=19)$ established RA, and not in SpA patients ( $n=45)$, which is consistent with data reported by Rao et al. Interestingly, this increased cTph cell frequency was observed only in seropositive RA patients with an active disease (DAS28 $>2.6, n=24$ ), whereas the numbers of cTph cells in established RA patients who had achieved remission (DAS28 <2.6, $n=23$ ) were not different from HC. Furthermore, Tph cells were present in the synovial fluid of seropositive RA $(n=4)$ but not of seronegative RA $(n=3)$ or $\operatorname{SpA}(n=3)$.

Conclusions: Tph cells may play an important role in the pathogenesis of seropositive but not seronegative RA. An increased cTph cell frequency is a marker of active, seropositive RA

REFERENCE:

[1] Rao DA, et al. Nature 2017;542(7639):110-114.

Disclosure of Interest: None declared

DOI: 10.1136/annrheumdis-2018-eular.3855

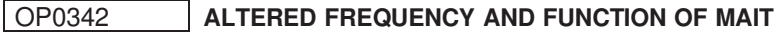 CELLS IN SYSTEMIC SCLEROSIS REVEALED BY HIGH DIMENSIONAL MASS CYTOMETRY AND TRANSCRIPTOME ANALYSIS}

B. Paleja ${ }^{1}$, A. Low ${ }^{2}$, P. Kumar ${ }^{1}$, S. Saidin ${ }^{1}$, A. Lajam ${ }^{1}$, L. D/O Thanna Bathi ${ }^{1}$, L. Lai ${ }^{1}$, C. Chua ${ }^{1}$, S. Albani ${ }^{1} .{ }^{1}$ Translational Immunology Institute; ${ }^{2}$ Department of Rheumatology and Immunology, Singapore General Hospital, Singapore, Singapore

Background: Systemic sclerosis (SSc) is an autoimmune disease characterised by excessive fibrosis of skin and internal organs, and vascular dysfunction ${ }^{1}$. Association of $\mathrm{T}$ and $\mathrm{B}$ cell subsets have been reported in SSc, however there is lack of systematic studies of functional relations between immune cell subsets in this disease $^{2,3,4}$. This lack of mechanistic knowledge hampers targeted intervention.

Objectives: In the current study we ought to determine differential immune cell composition and heterogeneity in peripheral blood of SSc patients and its impact on disease severity and progression.

Methods: Mononuclear cells from blood of SSc patients with interstitial lung disease (ILD, $n=10)$ or No ILD $(n=10)$ and healthy controls $(n=10)$ were analysed by mass cytometry using a 36 marker (cell-surface and intracellular) panel to aid in identification of major PBMC lineages including T cells, B cells, monocytes and NK cells and their subsets. Transcriptome analysis (m-RNA sequencing) was performed on sorted T and B cell subsets. Unsupervised clustering of mass cytometry data was performed using in-house developed analysis software MARVIS This software combines dimension reduction and clustering steps to identify all possible cellular subsets. Further, custom $\mathrm{R}$ scripts helped in identifying nodes that were differentially expressed between the study groups and also phenotype of these nodes.

Results: Unsupervised clustering performed revealed significant differences in the frequencies of $T$ cell and $B$ cell subsets. Most strikingly we identify a 3 fold decrease in frequencies of Va7.2+CD161+mucosal associated invariant $\mathrm{T}$ cells (MAIT) in SSc patients and 2 fold increase in total B cells, particularly 